DOI: $10.14451 / 1.171 .134$

\title{
СИСТЕМА ОЦЕНКИ РИСКОВ, ОБУСЛОВЛЕННЫХ ВЛИЯНИЕМ СУРОВЫХ КЛИМАТИЧЕСКИХ УСЛОВИЙ НА ЭКОНОМИКУ АРКТИЧЕСКОЙ ЗОНЫ РОССИЙСКОЙ ФЕДЕРАЦИИ
}

\author{
(C) 2019 Шнайдер Ольга Владимировна \\ кандидат экономических наук, доцент Департамента учета, анализа и аудита \\ Финансовый университет при Правительстве Российской Федерации \\ E-mail: shnaider-o@mail.ru \\ (c) 2019 Петров Александр Михайлович \\ доктор экономических наук, профессор Департамента учета, анализа и аудита \\ Финансовый университет при Правительстве Российской Федерации \\ E-mail:palmi@inbox.ru

\section{(C) 2019 Боровицкая Марина Владимировна} \\ кандидат экономических наук, доцент Департамента учета, анализа и аудита \\ Финансовый университет при Правительстве Российской Федерации \\ E-mail: geht066@mail.ru
}

Современное мировое сообщество все больше внимания уделяет системе оценки рисков. В настоящее время вопросы оценки рисков, обусловленных влиянием суровых климатических условий на экономику Арктической зоны РФ, являются наиболее дискуссионными и актуальными в связи с повышенным интересом ведущих мировых стран к данной части Земного полушария. Деятельность в области охраны окружающей среды приобретает неоспоримый интерес всего человечества, затрагивая при этом и тенденции развития подходов к экологическому и социальному анализу.

Ключевые слова: Арктика, экономика, Северный морской путь, социально-экономическое развитие, экосистема, устойчивость, климатические изменения, риски, стратегия.

Природная зона Арктики имеет свои особенности экосистем, обеспечивающих основу устойчивого социально-экономического развития данной территории Российской Федерации. В современных условиях особого внимания требует сложный механизм всевозможного изменения климата и последствия данных изменений с учетом влияния на биоресурсы, наземные, морские экосистемы, так как последствия климатического изменения сопряжено с определенными рисками, влияющими на устойчивое социально-экономическое развитие Арктической зоны Российской Федерации.

Экологическое состояние Земли обусловило оправданный интерес российских и зарубежных ученых в части климатических и экологических проблем. Одной из важных проблем последнего десятилетия является эколого-климатические проблемы Арктики, что оправдано следующим:

1. Арктика является наиболее уязвимой планетарной частью по природно-климатическим изменениям, темпы которых превышают имеющиеся природно-климатические изменения в других регионах нашей планеты.
2. Риски, связанные с присутствием человека и его жизнедеятельностью, оказывают негативное влияние на состояние различные экосистемы, в том числе морскую, пресноводную и наземную экосистемы. В свою очередь, изменением экосистемы арктического региона - это ключевые риски развития полярных регионов.

Арктические природно-климатические изменения имеют обратное воздействие на климат планеты в целом, и, опосредованно, на экологическую и микрохозяйственную мировую системы, определяя планетарную значимость климатических изменений в арктическом регионе.

Ивантер В.В. [1], Крюков В.А. [2], Лексин В.Н. [1], Порфирьев Б.Н. [1], и другие [3] считают, что «его геоэкономического значения, в том числе как перспективного источника природных ресурсов и пространства для организации новых, экономически выгодных транспортных маршрутов и реализации крупных наукоемких государственных проектов развития, потенциально способных стать двигателями долгосрочного экономического роста». Катцов В.М. и Порфирьев Б.Н. в оценке влияния человека на окружа- 
ющую среду пишут «количественная оценка влияния хозяйственной деятельности человека на наблюдаемое в течение последних десятилетий потепление Арктики представляет определенную проблему из-за присущей климатической системе естественной изменчивости, амплитуда которой в полярных широтах велика» [4].

Снижение экологических и природно-климатических рисков является актуальной задачей мирового сообщества. Важным аспектом при анализе системы оценки рисков арктической зоны, определенных влиянием суровых климатических условий на российскую социально-политическую и экономическую составляющую является то, что в последнее время резко повысилась геополитическая важность региона со стороны военно-политической составляющей.

В последнее время внешняя политика Китая направлена на расширение возможностей присутствия в Арктике. «Главное внимание уделяется стратегическому видению Китая об Арктике, особенностям формирования двустороннего и многостороннего сотрудничества по вопросам Арктики, также мнению российских экспертов об экономическом партнерстве между Россией и Китаем» [5, с. 43]. Внешняя стратегия Китая, учитывающая экономическое партнерство с Россией рассматривает основные пути развития в части: использования и расширения арктической транспортной системы; получения выхода к ресурсам Арктики; поиск бизнес-партнеров по реализации инвестиционных проектов и про- грамм в данном регионе.

Многостороннее и двустороннее сотрудничество Росси и Китая пройдет как минимум в шести направлениях (рисунок 1).

Ягья В.С., Харлампьева Н.К., Лагутина М.Л. приходят к выводу о том, что «на начальном этапе международного сотрудничества в Арктике полярные научные исследования становятся инструментом «мягкой силы», а в долгосрочной перспективе Китай включил Северный морской путь Российской Федерации в Экономический пояс и Морской шелковый путь Китая в XXI в.» [5, с. 43-50]. Пачаури Р.К. и Мейер Л.А. ориентируясь на мнение Межправительственной группы экспертов по изменению климата определяют, что потенциал адаптации рисков различных арктических экосистем являясь ключевым в краткосрочной перспективе с 2030 г. по 2040 г. и долгосрочной перспективе с 2080 г. по 2100 г. оценивается как незначительный [6, с. 14].

Порфирьев Б.Н., Терентьев Н.Е. в своей статье пишут «Специфика природно-климатических условий региона планеты в решающей мере определяется пространственно-географическим фактором. Огромная территория Арктики, охватывающая на суше земли, расположенные выше 66 33’ с.ш., и акваторию и острова Северного Ледовитого океана, обусловливает наличие в ее составе разнообразных и уникальных типов экосистем: наземных, пресноводных, морских и прибрежных» [7].

С учетом вышеизложенного следует отме-

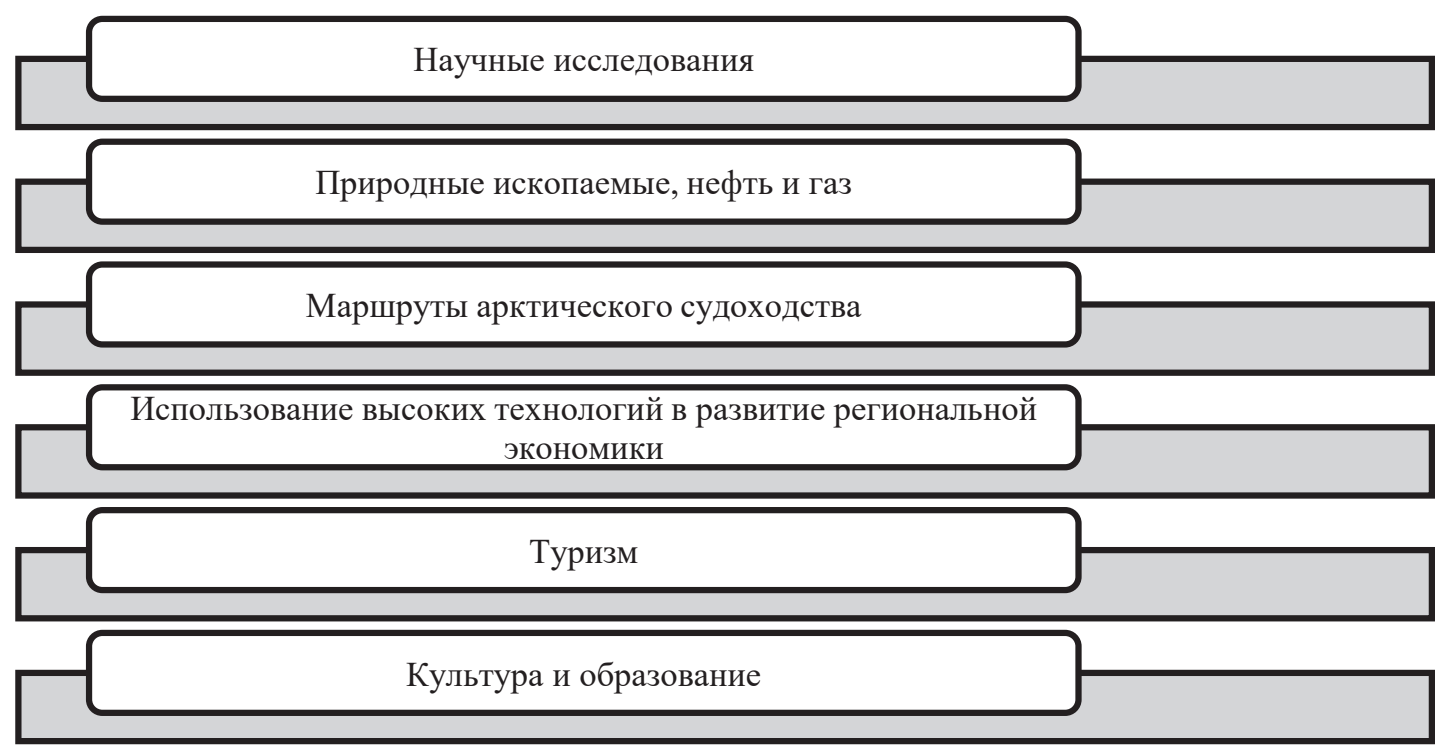

Puc. 1. Направления многостороннего и двустороннего сотрудничества Китая и России в арктическом регионе 
тить значение анализа экологических инвестиционных проектов направленно на развитие Арктики. Между тем, методические подходы к анализу и оценке эффективности долгосрочных экологических инвестиций требуют определенной актуализации и выделения лимитирующего фактора, обеспечивающего социальное развитие и устойчивость.

Отдельным исследованиям следует подвергнуть понятийный аппарат в части социального развития и социальной устойчивости, группы вовлеченных сторон, социально-экономические факторы и условия повышения эффективности деятельности организаций. В свою очередь оценка эффективности деятельности ориентирована на создание условий для реализации интересов собственников; оптимизацию механизма согласования интересов всех участников бизнеса; формирование эффективных коммуникаций.

На наш взгляд, интересна позиция Хэ Чжун, который определяет, что «Северный морской путь носит совершенно очевидный экономический характер и является важной составной частью Морского Шелкового пути XXI века» [8], что отвечает современным экономическим взаимоотношениям.

Российскими экспертами дается оценка того, что Россия во взаимодействии с Китаем можем выступать только в качестве младшего партнера. В первую очередь это подтверждается высоким темпом развития Китая, осваивающего новые технические рубежи. В этой связи Китай может вызвать тревогу у России в части своей безопасности.

Необходимо отметить то, что российское экспертное сообщество имеет полярную точку зрения в части перспективного развития сотрудничества России и Китая в Арктике. Объединяет полярность точек зрения экспертов общее восприятие возникающих барьеров со стороны северных держав арктического региона, которые оказывают влияние в рамках международного права и собственных двусторонних отношений с ними.

Филимонова Н. и Кривохиж С. видят «несовпадение в ряде случаев национальных интересов России и Китая в Арктике, эта группа экспертов не исключает отрицательного воздействия этого обстоятельства на весь ход развития российско-китайских арктических дел» [9].

Как на международном уровне, так и на на- циональном уровне проблемы объединения отдельных территории и субъектов арктической зоны Российской Федерации обусловлены угрозами долгосрочных геополитических и внутриэкономических интересов России. Несомненно, эффективная государственная политика в области развития территории Арктики требует комплексного, всестороннего отраслевого анализа, учитывающего социально-экономическую дифференциацию участника деятельности арктической зоны. Эффективная и рациональная политика отраслевого развития в арктическом регионе, вскроет острые проблемы регионов и обеспечит выбор актуальных и перспективных направлений.

По нашему мнению, социально-экономическую дифференциацию арктических регионов России следует рассматривать с учетом внутреннего потенциала каждого экономического субъекта, функционирующего в сложных климатических условиях.

В свою очередь, воздействие экономического субъекта на окружающую среду характеризуют индикаторы экологической результативности. Эти индикаторы отражают влияние экономического субъекта на состояние экосистемы, земли, воздуха, водного бассейна: посредством использования природных материалов, энергии, воды, биоразнообразия. Таким образом, выбросы и отходы, а также продукция и услуги экономического субъекта, должны соответствовать общепринятым нормативным требованиям и т.п.

Индикаторы экологической результативности в современном деловом пространстве хорошо регламентированы, по ним достигнуто наибольшее единство взглядов. Индикаторы могут быть выражены как в абсолютных, так и относительных значениях (например, использование электроэнергии на единицу выпущенной продукции). Абсолютные значения индикаторов экологической результативности экономических субъектов отражают масштаб (величину воздействия) его деятельности. Относительные индикаторы эффективности позволяют провести сравнительный анализ экономических субъектов.

В современном мире наиболее актуальными являются проблемы связанные с изменением климата из-за выброса парниковых газов, влияние деятельности экономических субъектов на изменение климата. Определяющие показатели экологической устойчивости экономического 
субъекта представляет рисунок 2 [10].

Примеры индикаторов в области экологической устойчивости экономического субъекта представлены в табл.

Необходимо отметить, что право выбора о публикации в отчетности об устойчивом развитии экономического субъекта индикаторов экологической устойчивости остается за самим субъектом. Методика анализа и оценки рисков финансово-хозяйственной деятельности экономического субъекта определяется с учетом его отраслевой специфики и видов деятельности, территориального месторасположения и уровня конкуренции, условий социального и политического воздействия и т.п.

В заключении статьи необходимо отметить, что система оценки рисков, обусловленных влиянием суровых климатических условий на экономику арктической зоны РФ остается открытым дискуссионным вопросом, который требует глубокого исследования и обсуждения, как на национальном, так и на международном уровне.

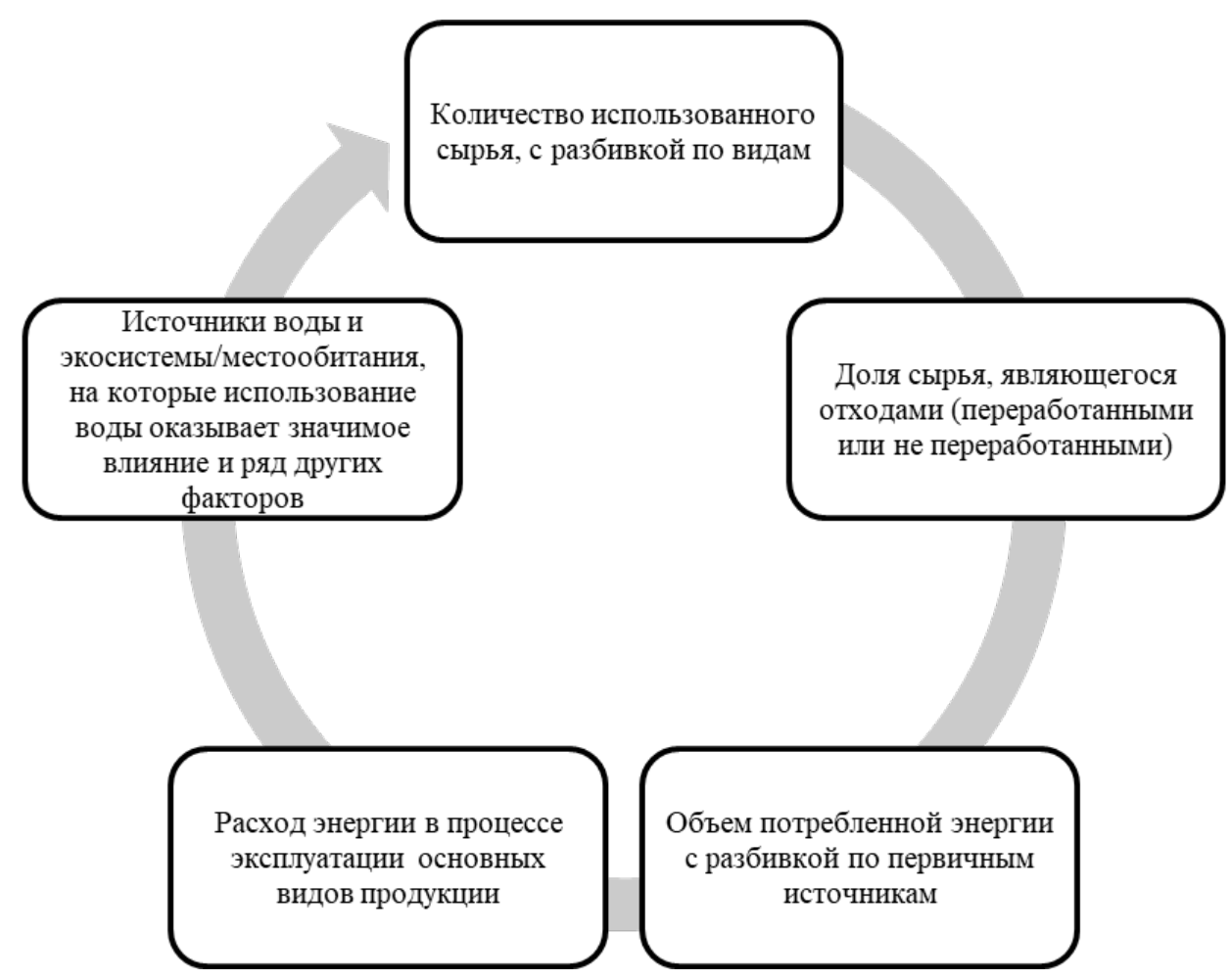

Puc. 2. Определяющие показатели экологической устойчивости экономического субъекта

Таблица. Индикаторы экологической устойчивости экономического субъекта

\begin{tabular}{|c|c|}
\hline Аспект анализа и мониторинга & Индикаторы \\
\hline Выбросы парниковых газов & $\begin{array}{l}\text { Объем выбросов парниковых газов: } \\
\text { - по объектам выбросов парниковых газов; } \\
\text { - по методике расчета уровня парниковых газов; } \\
\text { - по периодам. } \\
\text { Общая характеристика системы сбора и верификации данных, } \\
\text { независимый аудит. }\end{array}$ \\
\hline $\begin{array}{l}\text { Энергоэффективность } \\
\text { и энергосбережение }\end{array}$ & Количество использованных энергоресурсов \\
\hline
\end{tabular}




\section{Библиографический список}

1. Ивантер В.В., Лексин В.Н., Порфирьев Б.Н. Арктический мегапроект в системе государственных интересов и государственного управления // Проблемный анализ и государственно-управленческое проектирование. 2014. № 6. С. 6-24.

2. Крюков В.А. Арктика - каким ресурсам отдать предпочтение? // Проблемный анализ и государственно-управленческое проектирование. 2014. № 3. С. 45-66.

3. Circum-Arctic Resource Appraisal: Estimates of Undiscovered Oil and Gas North of the Arctic Circle - CARA. U.S. Geological Survey, 2008. http://energy.usgs.gov/RegionalStudies/Arctic.aspx

4. Катцов В.М., Порфирьев Б.Н. Климатические изменения в Арктике: последствия для окружающей среды и экономики. // Арктика: экология и экономика. 2012. № 2. С. 66-79.

5. Ягья В.С., Харлампьева Н.К., Лагутина М.Л. Арктика - новый регион внешней политики Китая // Вестник РУДН. Серия Международные отношения. 2015, № 1

6. IPCC, 2014: Climate Change 2014: Synthesis Report. Contribution of Working Groups I, II and III to the Fifth Assessment Report of the Intergovernmental Panel on Climate Change Core Writing Team, R.K. Pachauri and L.A. Meyer (eds.)]. IPCC, Geneva, Switzerland, $151 \mathrm{pp}$.

7. Порфирьев Б.Н., Терентьев Н.Е. Эколого-климатические риски социально-экономического развития Арктической зоны Российской Федерации // http://ecovestnik.ru/index.php/2013-07-07-02-13-50/kommentrijspecialista/2420-ekologo-klimaticheskie-riski-sotsialno-ekonomicheskogo-razvitiya-arkt

8. Хэ Чжун. Совместные содействия возрождению Великого шелкового пути // Китай. 2014. № 5. С. 7.

9. Филимонова Н., Кривохиж С. Российский взгляд на роль Китая в Арктике. URL: http://inosmi.ru.

10. Бариленко В.И., Бердников В.В., Ефимова О.В., Булыга Р.П. Основы бизнес-анализа: учебное пособие / под ред. В.И. Бариленко. Москва, 2014.

Поступила в редакцию 14.02.2019 